\title{
Os Estudos Culturais como novas Humanidades ${ }^{1}$
}

\author{
Moisés de Lemos Martins
}

\begin{abstract}
RESUMO
É meu propósito, neste estudo, argumentar a ideia de que os Estudos Culturais podem ser encarados como novas humanidades. Os Cultural Studies centram a atenção nos estudos étnicos, pós-coloniais, comunicacionais, antropológicos, etnográficos e feministas, e apenas "muito marginalmente" têm-se interessado pela literatura e pelos estudos literários (Aguiar e Silva, 2008). Mas são precisamente esses domínios, investidos pela 'Social Science', e não pelas 'Arts', que se constituem como pedra de toque da modernidade. E é neles que se joga, hoje, em grande medida, a ideia que temos do humano. A interrogação que hoje é feita, tanto sobre o humano como sobre a modernidade, tem como pano de fundo a translação tecnológica da cultura, da palavra para a imagem (Martins, 2011a). A minha proposta tem em atenção esse debate, sublinhando entretanto o compromisso que os Estudos Culturais têm com atual e o contemporâneo, o que também quer dizer, com o presente e o quotidiano.
\end{abstract}

\section{Palavras-chave}

Estudos Culturais; novas Humanidades; Tecnologias da Informação e da Comunicação; atual; contemporâneo; imagem

\section{INTRODUÇÃO}

As humanidades literárias são habitadas pelo espírito de preservação de um corpus de saber, erigido ao longo de séculos e que se pretende transmitir às novas gerações. Mas, hoje, já não é apenas disso que se trata. Para darmos um exemplo, verificamos que o espírito que anima a descrição dos destinatários do doutoramento em Estudos Culturais (UM/UA), no site deste Programa doutoral, é o da resposta aos novos desafios colocadas pela sociedade contemporânea:

(1) "O Programa Doutoral de Estudos Culturais dirige-se à formação de profissionais nas áreas da criação, promoção, animação, mediação e divulgação cultural, bem como responsáveis por bibliotecas públicas, editoras, centros de produção de informação e de eventos culturais, responsáveis culturais de embaixadas, institutos, fundações, centros culturais, empresas ligadas ao turismo e hotelaria, entre outros";

(2) e logo a seguir: "A formação de investigadores nesta área tem, igualmente, como objetivo qualificar especialistas capazes de trabalhar em equipas multidisciplinares na resolução de problemas como o desenvolvimento sustentável, a ética empresarial, os estudos filmicos, de género, os media, a internet, pós-colonialismo, preservação de património material e imaterial, etc.";

(3) e para finalizar: "A investigação nesta área procurará ainda responder à necessidade de formação de pesquisadores capazes de produzir investigação em ambientes que exijam a articulação de diversas áreas científicas como Comunicação, História, Filosofia, Sociologia, Psicologia, Literatura ou Património" (http://estudosculturais.com/portal/apresentacao/)².

\footnotetext{
' Este artigo foi originalmente publicado em 2015 na revista Biblos, 1, 3. ${ }^{a}$ série. DOI http://dx.doi.org/10.14195/0870-4112

${ }^{2}$ No âmbito deste Programa Doutoral em Estudos Culturais (UM/UA), é de salientar a criação da Rede em Estudos Culturais/
} 
Antes de mais nada, gostaria de sublinhar o facto de nem uma palavra ser dita sobre a formação de professores, que todavia foi no passado o objetivo quase exclusivo dos cursos de humanidades. É verdade, por outro lado, que as filologias, tanto as clássicas como as contemporâneas, sempre constituíram uma introdução à cultura e ao pensamento próprios, e também à cultura e ao pensamento dos povos e das gentes, tanto remotos como próximos no tempo e na geografia (Fidalgo, 2008, p. 10). Mas nas circunstâncias pós-coloniais de um mundo mobilizado nas suas práticas por toda a espécie de tecnologias, sobretudo por dispositivos tecnológicos de comunicação, informação e lazer, haverá que interrogar a racionalidade ocidental a partir dos mundos não ocidentais, na relação intrincada que estes têm com os antigos povos coloniais3.

Também George Steiner em No Castelo do Barba Azul. Notas para uma Redefinição da Cultura, pronuncia em "Amanhã", título do quarto e último capítulo deste ensaio, uma palavra de lucidez, ao mesmo tempo trágica e heróica, como que abrindo uma última porta para a noite, sendo que a noite por onde entra connosco é a tecnologia: "Não podemos optar pelos sonhos da ignorância. Abriremos, penso eu, a última porta do castelo embora ela possa levar, ou talvez porque ela pode levar, a realidades que estão para além da capacidade do entendimento e controlo humanos. Fá-lo-emos com a lucidez desolada, que a música de Bartok prodigiosamente nos comunica, porque abrir portas é o trágico preço da nossa identidade" (Steiner, 1992, p. 141)4.

Cultural Studies Network, em dezembro de 2014, uma rede de cooperação de instituições culturais, educativas e artísticas, que cria condições objetivas para a produção de conhecimento científico sobre arte, cultura e sociedade em Portugal, na perspetiva dos Estudos Culturais. Com efeito, esta Rede torna possível que os doutorandos do Programa Doutoral em Estudos Culturais possam investigar os processos artísticos, educativos e culturais, realizados nas instituições parceiras, ou então, estudar os seus acervos artísticos, bibliográficos e documentais. Por outro lado, a Rede desenvolver-se-á no sentido da partilha e divulgação de informações de agenda cultural dos respetivos membros no site do doutoramento. Finalmente, a Rede constituir-se-á em conselho consultivo de apoio às linhas de investigação deste Programa Doutoral nos próximos anos, colaborando ativamente no desenvolvimento académico do Programa. http://estudosculturais.com/portal/redes/ cultural-studies-network/

Neste momento a rede é constituída pelas seguintes entidades: Culturgest; Teatro Nacional S. João; Fundação de Serralves; Casa da Música; Instituto Internacional Casa de Mateus; Museu de Aveiro; Teatro Aveirense; Museu da Imprensa, Theatro Circo de Braga; Centro Cultural Vila Flor de Guimarães; Casa das Artes de Famalicão; Irenne - Associação de investigação, prevenção e combate à violência e exclusão; INATEL; Movimento Democrático de Mulheres; Direção Regional da Cultura da Zona Norte; Direção Regional da Cultura da Zona Centro.

${ }^{3}$ Neste sentido chamo à atenção para a tese de doutoramento em Ciências da Comunicação, na especialidade de Comunicação Intercultural, defendida na Universidade do Minho, em 2013, por Maria de Lurdes Macedo, intitulada, "Da Diversidade do Mundo ao Mundo Diverso da Lusofonia: A Reinvenção de uma Comunidade Geocultural na Sociedade em Rede" (Macedo, 2013) http://repositorium.sdum.uminho.pt/handle/1822/28851

${ }_{4}^{4}$ George Steiner escreveu este ensaio sobre a cultura contemporânea, em 1971, ainda longe, portanto, da grande subversão das práticas e dos consumos culturais introduzidos pelas tecnologias eletrónicas. E o título, No Castelo do Barba Azul, tem tanto de sugestivo como de inquietante. Todos nos lembramos do conto tradicional em que um tenebroso senhor, de barba azul, guardava um terrível segredo bem aferroado no quarto do seu castelo. Era nesse verdadeiro quarto dos horrores que escondia os cadáveres esquartejados das sucessivas mulheres com quem se casara, mas que invariavelmente assassinara. O compositor húngaro, Bella Bartok, fez deste conto tradicional o libreto de uma das suas óperas. E Steiner, logo na abertura do seu ensaio, convoca uma personagem de Bartok, querendo com ela precisar todo o sentido da viagem que quer empreender connosco. Escreve então: "Dir-se-ia que estamos, no que se refere a uma teoria da cultura, no mesmo ponto em que a Judite de Bartok, quando pede para abrir a última porta para a noite" (Steiner, 1992, p. 5). Abrir a última porta para a noite! É isso o que faz Steiner neste ensaio, que é uma porta aberta sobre "O grande tédio" (título do primeiro capítulo); sobre "Uma temporada no Inferno" (título do segundo capítulo), sobre a "Pós-cultura" (título do terceiro capítulo"); sobre "Amanhã" (título do quarto e último capítulo). Sobre este assunto, escrevi "Technologie et Rêve d'Humanité" (Martins, 2011b). 
Seguindo a sugestão de Steiner, de abrir portas no castelo da cultura, a porta do castelo que hoje há mesmo que abrir é a da tecnologia. E a minha proposta sobre as novas humanidades é exatamente essa: debater a técnica e o papel que as novas tecnologias, que incluem os média, têm na redefinição da cultura, ou seja, na delimitação do humano. Trata-se de uma porta que não podemos deixar de abrir, uma vez que ela constitui hoje "o trágico preço da nossa identidade", como podemos dizer, retomando a fórmula de Steiner.

Em meu entender, o novum da experiência contemporânea é precisamente este, o de a techné se fundir com a bios. Num momento em que, com as biotecnologias, se fala da clonagem, de replicantes e de cyborgs, de hibridez, de pós-orgânico e de trans-humano, e em que, com as novas tecnologias da informação, ocorre a crescente miniaturização da técnica e a imaterialização do digital, neste tempo de biotecnologias e de novas tecnologias da informação, dizia, dá-se a completa imersão da técnica na história e nos corpos.

Esta imersão da técnica na vida - a fusão da bios com a technê —, é particularmente evidente com as biotecnologias, os implantes, as próteses, a engenharia genética. Mas acontece, também, no caso das novas tecnologias da imagem. Aquilo a que hoje chamamos as tecnologias da comunicação e da informação, especificamente a fotografia, o cinema, a televisão, os jogos eletrónicos, o multimédia, as redes cibernéticas e os ambientes virtuais, funcionam em nós como próteses de produção de emoções, como maquinetas que modelam em nós uma sensibilidade puxada à manivela (Martins, 2002b, pp. 181-186; 2007b, pp. 5-7).

Se bem observarmos, vemos esta tese declinada por inteiro em La Monnaie Vivante, de Pierre Klossowski (1997): "desejo, valor e simulacro", aí está "o triângulo que nos domina e nos constitui na nossa história, sem dúvida desde há séculos", como bem assinala Michel Foucault na carta que introduz a obra (Foucault citado em Klossowski, 1997, p. 9).

A interrogação, tanto sobre o humano como sobre a modernidade, tomando como linha de rumo os Estudos Culturais, deve-se, fundamentalmente, por um lado, à assunção do princípio de historicidade do conhecimento (Martins, 1994) e, por outro lado, à translação tecnológica da palavra para a imagem (Martins, 2011a).

O princípio de historicidade do conhecimento significa que o saber é sobretudo uma experiência e que a verdadeira experiência é uma experiência dos limites ou da finitude humana.

Por sua vez, o movimento de translação tecnológica, que ocorre na civilização ocidental, da palavra para a imagem, é um movimento, que embora mobilize os indivíduos para o mercado, desativando-os como cidadãos (Martins, 2011a), tem grande "potencial humanístico" (Fidalgo, 2008, p. 7). Com efeito, não menos que as disciplinas tradicionais dos cursos de humanidades, como a Literatura, a Filosofia e a História, também os Estudos Culturais constroem modelos de descrição e resolução de problemas, elaboram estratégias de abordagem dos dilemas com que os seres humanos se confrontam, individual e coletivamente, e levantam e formulam as questões essenciais sobre os valores, os objetivos e o sentido da ação humana. 
A minha proposta de trabalho consiste, pois, em debater a técnica e o papel que as novas tecnologias, que incluem os média, têm na redefinição da cultura, ou seja, na delimitação do humano, sublinhando o compromisso que os Estudos Culturais têm com o atual e o contemporâneo, o que também quer dizer, com o presente e o quotidiano.

\section{A mobilizaÇÃo TECNOLÓgiCA}

Injetada pelas tecnologias da informação e da comunicação, a civilização moderna é acelerada infinitamente e o humano é mobilizado totalmente para o presente e para o mercado (Virilio, 1995; Sloterdijk, 2000; Martins, 2010b)5 , não parando ambos de se deslocar "dos átomos para os bits" (Negroponte, 1995, p. 10). Esta imersão da técnica na vida e nos corpos tem como consequência que a ideologia se desloque para a 'sensologia', ou seja, que das ideias nos desloquemos para as emoções ${ }^{6}$; e também, que uma sociedade de fins universais se desloque para uma sociedade de meios sem fins (Agamben, 1995), com a tecnologia a desativar os princípios teleológico e escatológico que fundaram o Ocidente e o fim da história, com génese e apocalipse, a ser desmantelado e a dar lugar ao instantaneísmo.

São estas as circunstâncias em que a palavra como logos humano (como razão humana) entra em crise, tendo o homem deixado de ser "animal de promessa" (Martins, 2009; 2002c), como o havia definido Nietzsche (1887, p. II, \1), porque a sua palavra já não é capaz de prometer. No nosso tempo deu-se, com efeito, a translação do regime da palavra para o regime da imagem tecnológica. E essa translação deixou-nos "em sofrimento de finalidade" (Lyotard, 1993, p. 93; Martins, 2002a; 2002C).

Num longo texto jornalístico sobre o que designou como "A crise das Humanidades", Carlos Reis, Professor catedrático da Universidade de Coimbra (Público, 25.10.2005), colocou na origem da crise, entre outras razões, "a deslegitimação progressiva da palavra escrita (e lida), em benefício de discursos dominados pela imagem", e também, "a gradual perda de poder simbólico de saberes com tradição na cultura ocidental (a Filosofia, a Literatura, a História)", e ainda, "a hegemonização televisiva e a brutal tabloidização de uma vida pública reduzida à indigência".

\footnotetext{
5 "Mobilização total" é uma expressão que Ernest Jünger utiliza pela primeira vez no ensaio Die Totale Mobilmachung, em 1930. Jünger refere-se aí à lição que havia retirado da Primeira Grande Guerra, onde combatera. Ao mobilizar a energia em que transformara a existência por inteiro, a Grande Guerra estabelecia uma ligação total ao mundo do trabalho: "A exploração total de toda a energia potencial, de que são exemplo estas oficinas de Vulcano construídas pelos Estados industriais em guerra, revela, sem dúvida, da maneira mais significativa, que nos encontramos no dealbar da era do Trabalhador, e que esta requisição radical converte a guerra mundial num acontecimento histórico mais importante do que a Revolução Francesa". Além disso, tão ou mais importante neste processo do que a técnica, que é a face ativa da mobilização, é a resposta humana, ou seja, o facto de o trabalhador se mostrar disponível para ser mobilizado (Jünger, 1990, p. 115). Quanto à aceleração e à mobilização da época, lembremos, especificamente, as palavras de Jünger (1990, p. 108): "a mobilização total [ ... ] é, em tempo de paz como em tempo de guerra, a expressão de uma exigência secreta e constrangedora à qual nos submete esta era das massas e das máquinas". Sobre a "mobilização infinita numa sociedade de meios sem fins", ver, também, Moisés de Lemos Martins (2010b).

6 A 'sensologia' foi tematizada por Mario Perniola no ensaio Del sentire, em 1991. Exprime a importância crescente das sensações (e das emoções), num movimento de abandono da ideologia. Todavia, nesta passagem da ideologia para a 'sensologia', Perniola vê uma experiência do que se repete, uma experiência 'do já sentido', e não uma experiência original, como se fosse impossível experimentar pela primeira vez o que quer que seja.
} 
Com efeito, a palavra havia inscrito o Ocidente numa história de sentido, entre uma génese e um apocalipse. $E$ também havia inscrito o Ocidente num regime de analogia, com todas as coisas a remeterem para um criador e com todas as palavras a sinalizarem um sentido/um caminho único. Éramos guiados pelas estrelas do céu, especialmente por uma, que tendo nascido a Oriente conduziu o Ocidente por mais de dois mil anos.

Em contrapartida, o regime da imagem tecnológica é um regime imanente, um regime autotélico, uma autarcia de sentido, com imagens profanas, laicas e mundanas. Em vez de olharmos para as estrelas, é para os ecrãs que agora olhamos, é para as telas, para as passerelles, assim como para os simulacros que nelas se movimentam. Em vez da estrela que há dois mil anos ilumina o Ocidente, temos agora os holofotes das grandes paradas mediáticas, uma luz de cuja artificialidade nos damos conta quando a corrente elétrica falha.

Expulsos, todavia, do regime da palavra, ficamos marcados pela instabilidade e o desassossego. E passamos a rever-nos sobretudo nas figuras que acentuam a nossa condição transitória, tacteante, contingente, fragmentária, múltipla, labiríntica, enigmática, imponderável, nomádica e solitária?

\section{AS CIÊNCIAS DA COMUNICAÇÃO COMO NOVAS HUMANIDADES}

Os Cultural Studies são uma tradição epistemológica das Ciências Sociais e Humanas, que a partir dos anos sessenta e setenta do século passado, deslocou a reflexão sobre a cultura, de um entendimento centrado na relação cultura/nação e no privilégio dado ao ensino da língua e da literatura, para uma aproximação da cultura aos estilos de vida dos grupos sociais, o que significa uma atenção prestada ao quotidiano das massas e à mudança social, uma atenção particularmente centrada na receção e no consumo dos média, nos públicos e nas audiências.

De facto, mais do que qualquer outra corrente teórica das Ciências Sociais e Humanas, os Estudos Culturais distinguem-se por habitarem o território do atual e do contemporâneo e por se estabelecerem no presente e no quotidiano (Martins, 2011a). E as Ciências da Comunicação têm a sua génese e o seu destino associados ao incremento dos Estudos Culturais. Não é de modo nenhum por acaso que a primeira revista britânica de Cultural Studies, fundada em 1979, em Birmingham, tenha o título esclarecedor de Media, Culture and Society.

Dada esta associação das Ciências da Comunicação aos Estudos Culturais, é hoje habitual as Ciências da Comunicação serem consideradas como "as novas humanidades" (Fidalgo, 2008). As Ciências da Comunicação inscrevem-se nesta tradição epistemológica das Ciências Sociais e Humanas que "dos anos sessenta e setenta para cá não mais parou de desessencializar e de deselitizar os territórios culturais, deslocando os estudos

\footnotetext{
${ }_{7}$ Como exercício que ilustra a nossa condição transitória, labiríntica, enigmática e solitária, ver o estudo que realizei sobre os desfiles de moda do estilista inglês Alexander McQueen (Martins, 2013) http://estudosculturais.com/revistalusofona/ index.php/rlec/article/view/12/38 Ver também "Médias et Mélancolie", que declina as vertigens trágicas, barrocas e grotescas da condição humana, debruçando-se sobre o tema 'Mercy Street', de Peter Gabriel (Martins, 2011c). http://repositorium.sdum.uminho.pt/handle/1822/23866
} 
da cultura da exclusiva atenção prestada à língua nacional, à literatura de um país, ao texto literário, às grandes obras da música, pintura e escultura, e aos escritores, músicos e artistas, para trazer a debate os públicos, os utentes, os amadores e a criatividade nas margens e em artes menores, como a fotografia, a banda desenhada, o cartoon, a literatura de cordel, a arte e a música pop, os grafittis, o design gráfico..." (Martins, 2010c).

Tratando-se, além disso, de uma tradição que subverte "os supostos códigos naturais da masculinidade e da feminilidade, e a rígida e dominante definição da sexualidade", é uma tradição que se arrisca, mesmo, "a navegar para outros mundos que não os ocidentais, nas relações intrincadas que esses mundos têm com os antigos colonizadores, com as minorias étnicas e com as identidades multiculturais" (Martins, 2011a, p. 41-42).

Contemporâneas do movimento de aceleração mundial de bens culturais, pela mobilização tecnológica do planeta, e da assunção da solidariedade colectiva, que tem em vista a nossa segurança global, contemporâneas igualmente do processo de mundialização dos riscos ecológicos e ambientais, as Ciências da Comunicação acompanham, por outro lado, o nosso atual desassossego pelas consequências sociais e culturais das biotecnologias, que fundem numa amálgama o humano e o não humano (Martins, 2010c, pp. 80-81).

É sem dúvida por se instalarem no atual e no contemporâneo e por habitarem o presente e o quotidiano que as Ciências da Comunicação estão associadas aos novos territórios de investigação nas Ciências Sociais e Humanas: os novos grupos sociais (de produtores, criadores e divulgadores culturais), os consumos culturais (hábitos de leitura, de ida ao teatro, ao cinema, a concertos, a museus, a exposições de arte, hábitos de utilização da Internet), os estilos de vida, os gostos culturais, os públicos da cultura, os estudos de género, os estudos das sub-culturas juvenis (urbanas e sub-urbanas), os estudos de recepção dos média por jovens e adultos, e por públicos particulares como o das crianças, dos idosos e das minorias étnicas, os estudos sobre os usos dos dispositivos tecnológicos de comunicação, informação e lazer (Internet, iPod, iPad, telemóveis, etc.), os estudos sobre as identidades étnicas, os estudos pós-coloniais, os estudos sobre as indústrias culturais: moda, turismo, férias, museus, publicidade, cinema, televisão, rádio, imprensa escrita, novos média, jogos eletrónicos. Numa palavra, vamos ver as Ciências da Comunicação a revalorizar o sujeito, os públicos e os consumos de média, enfim, as culturas do ecrã (Martins, 2011a, p. 42).

Como enredo teórico, que adota o paradigma da historicidade, as Ciências da Comunicação relativizam, entretanto, a unidade de análise da sociologia clássica, que era a classe social, e valorizam, sobretudo, a idade, a escolaridade, o género e a identidade étnica. Relativizam, também, a categoria de ideologia, que é sobretudo uma categoria associada à classe social, e concentram-se na atenção dada à hegemonia dentro de um campo específico de relações de força e dominação, primeiro num entendimento gramsciano de hegemonia, depois no seu entendimento foucaultiano de "estados de poder", e ainda na caracterização bourdieusiana das "relações de força", num campo social específico de posições assimétricas (Ibidem) ${ }^{8}$.

\footnotetext{
${ }^{8}$ Esta secção, "As Ciências da Comunicação como novas humanidades", retoma a linha de argumentação, e mesmo o próprio texto, de dois estudos que já publiquei (Martins, 2010c, pp. 79-81; e 2011a, pp. 41-42).
} 


\section{O CONTEMPORÂNEO - UM IMAGINÁRIO MELANCÓLICO}

A tradição aristotélica que fez o Ocidente apoia-se no logos soberano, de formas lógicas com premissas claras, que concluem o certo e o verdadeiro. Apoia-se também no pathos, ordenado pela síntese redentora do logos, e no ethos, de formas elevadas, superiores, definidas pelo logos, que orienta para a ação. Em contrapartida, o nosso tempo, que é a expressão de uma sociedade mediática e tecnológica, é dominada pelo pathos, em que as sensações, as emoções e as paixões desativaram a centralidade do logos e do ethos (Martins, 2002a).

Richard Rorty (1994, p. 37) salientou que, "Em larga medida, a retórica da vida intelectual contemporânea mantém como evidente que a finalidade da pesquisa científica, cujo objecto é o homem, consiste em compreender as 'estruturas subjacentes', os 'invariantes culturais' ou os 'modelos biologicamente determinados'”. 'Estruturas subjacentes', 'invariantes culturais', 'modelos biologicamente determinados', quer isto dizer, uma realidade objetiva. E o conhecimento estaria em correspondência com ela ${ }^{9}$.

Dizer que abandonámos um regime centrado na palavra, o regime literário, e que entrámos num regime da imagem, significa que substituímos um regime que se fundava na afinidade entre a razão e a verdade, com o conhecimento a corresponder a uma realidade objetiva, por um regime fundado no princípio da historicidade do conhecimento, passando o modo de ser da razão a ser compreendido como uma interpretação (Martins, 1994, p. 7).

A ideia de que a verdade do conhecimento é uma interpretação é uma conquista do nosso tempo, que foi anunciada e trabalhada por mais de um século. Os nomes mais emblemáticos desta conquista são Nietzsche, com a crítica da metafísica, pela proposta da ideia de jogo, interpretação e signo sem verdade presente; Freud, com a crítica da presença do ser a-si-próprio, quer dizer, a crítica da consciência, do sujeito, da identidade em si próprio, da proximidade e da propriedade de si próprio; e Heidegger, com a destruição da metafísica, a destruição da ontoteologia, a destruição da determinação do ser como presença (Derrida, 1967, p. 412).

Os Estudos Culturais inscrevem-se neste paradigma da historicidade, adotando o ponto de vista de que é indissolúvel o vínculo estabelecido entre compreensão e situação, interpretação e preconceito, conhecimento e crença, teoria e prática (Gadamer, 1976, p. 139). Quer isto dizer que os Estudos Culturais exprimem um compromisso com atual e o contemporâneo. E exprimindo esse compromisso, vão fixar-se no presente e no quotidiano.

O regime da palavra dava-nos um fundamento seguro, um território conhecido e uma identidade estável. O abandono deste regime e a sua substituição pelo regime da imagem concretizam a cinética de um mundo bem distinto, um mundo inseguro, desconhecido e instável. E a assunção dos Estudos Culturais como as novas humanidades exprime a natureza de uma sensibilidade, que declina as atuais vertigens da cultura

\footnotetext{
${ }^{9}$ Hoje, a 'realidade objetiva' são, sobretudo, as “necessidades sociais práticas". E por necessidades sociais práticas, quero dizer as injunções do mercado para a 'qualidade', a 'excelência', a 'empregabilidade', a 'competitividade', a 'eficácia', o 'desempenho' e a 'performance'. Parece ser este o ersatz das 'estruturas subjacentes' e dos 'invariantes culturais', a que o conhecimento deve acomodar-se, por estar, soi-disant, em correspondência com ele.
} 
contemporânea, com o humano a ser cada vez mais identificado pelo seu caráter instável, sinuoso, viscoso, titubeante e labiríntico. ${ }^{10}$

Neste contexto, é também subvertido o regime da narrativa assente em formas clássicas, de linhas direitas e de superfícies claras. Cada vez mais, vamos encontrar no seu lugar formas barrocas, de linhas curvas, de dobras, e de superfícies côncavas e sombrias. E do mesmo modo, as formas dramáticas, com as personagens a viverem contradições redimidas por uma síntese, dão lugar a formas trágicas, em que as personagens vivem contradições que nenhuma síntese vai resolver. E cada vez menos vamos encontrar formas sublimes a darem corpo à narrativa, indicando um mundo elevado. Agora, são cada vez mais ostensivas as formas grotescas, caracterizadas pela desproporção e pela fealdade"

O abandono do regime da palavra, ou seja, do regime literário, significa, sem dúvida, o abandono da racionalidade clássica, uma racionalidade fundada no logos, um discurso, que é também razão. Esta racionalidade assenta em juízos de verdade e falsidade, em estratégias retórico-argumentativas, sendo os seus efeitos persuasivos. Importa-Ihe, sobretudo, a validade das proposições, expressa em raciocínios retóricos. Esta racionalidade liga quem produz o discurso e quem o recebe, e articula-se com um ethos, que estabelece a lógica do dever-ser. ${ }^{12}$

Ao falarmos da deslocação do centro de gravidade do logos e do ethos para o pathos, coloca-se a questão da retração da razão, o que torna problemática a questão da comunidade, ou seja, a questão do espaço público, da opinião pública, da cidadania e da democracia. No regime da imagem, o humano não deixa de ser interrogado. Mas já não se trata apenas de construirmos a comunidade humana em termos aristotélicos, através de silogismos retóricos, que são fundados na verosimilhança, e das suas estratégias argumentativas; trata-se também de a construirmos através dos sonhos, ou seja, através dos percursos figurativos da imagem, enfim, através do imaginário (Durand, 1969).

A razão (o logos, mesmo que seja o logos retórico, e o ethos) demonstra e persuade. Por sua vez, a imagem (enquanto signo inscrito num certo tipo de imaginário, ou seja, num sistema de sonhos) seduz e fascina.

Neste contexto, os média e as indústrias da imagem (sejam elas a fotografia, o cinema, a televisão, o vídeo, o computador, o multimédia, a publicidade, os jogos

\footnotetext{
${ }^{10}$ A propósito das atuais vertigens da cultura, convoco dois textos em que analiso, num, com o título "Médias et mélancolie - Le tragique, le baroque et le grotesque", o tema 'Mercy Street', de Peter Gabriel, já referido atrás (Martins, 2011c, pp. 17-21); e noutro, com o título "La nouvelle érotique interactive", o álbum "All Is Full of Love", de Björk (Martins, $2007 \mathrm{a}, \mathrm{pp}$. 21-27). Convoco, também, o seguinte trecho de Bernardo Soares, do Livro do Desassossego: "Preciso explicar-lhe que viajei realmente. Mas tudo me sabe a constar-me que viajei, mas não vivi. Levei de um lado para o outro, de norte para sul ... de leste para oeste, o cansaço de ter tido um passado, o tédio de viver um presente, e o desassossego de ter que ter um futuro. Mas tanto me esforço que fico todo no presente, matando dentro de mim o passado e o futuro" (Bernardo Soares, 1998, p. 482).

11 Sobre as formas trágicas, barrocas e grotescas da cultura contemporânea, ver Martins, 2013, 2011c, 2007a, 2002d.

${ }^{12}$ Sem dúvida, porque adota a língua como modelo para a análise de todos os sistemas semiológicos, inclusive para a análise dos sistemas de imagens, Roland Barthes defendeu na "Rhétorique de l'image" que era absurdo apresentar imagens sem palavras: "É possível, sem dúvida, encontrar imagens sem palavras, mas apenas a título paradoxal, em alguns desenhos humorísticos; a ausência de palavras recobre sempre uma intenção enigmática" (Barthes, 1964, p. 43, nota 4). Também eu próprio, na linha de Barthes, tomei a língua, analogicamente, como modelo para a análise dos outros sistemas semiológicos, em A linguagem, a verdade e o poder - Ensaio de Semiótica Social (Martins, 2002b).
} 
eletrónicos, os ambientes virtuais, a moda, o turismo, as férias...) são dispositivos de imagens, tanto como de palavras. Mas embora também demonstrem e persuadam pela palavra, por slogans, por exemplo, o que com elas acontece, sobretudo, é seduzirem-nos e fascinarem-nos. Diante dos média, os cidadãos são confrontados com estratégias retóricas (conscientes); e são igualmente confrontados com uma travessia, porque constituem um território obsidiado por imagens, que autorizam os mais diversos percursos figurativos (inconscientes).

É esse o sentido do livro que escrevi, com o título Crise no castelo da cultura - Das estrelas para os ecrãs (Martins, 2011a), uma proposta que dá conta da deslocação do logos e do ethos para o pathos, das proposições para as imagens, do consciente para o inconsciente, da retórica para o percurso figurativo, da persuasão para a sedução e o fascínio, dos média como dispositivos discursivos, de sentido exclusivamente argumentativo, para os média como dispositivos de imagens, com uma "memória sensorial, afetiva a e corporal"13.

\section{A ESTETIZAÇÃo DA EXPERIÊNCIA CONTEMPORÂNEA}

Em todas as épocas, as civilizações sempre se colocaram a questão do humano. A civilização da imagem não pode, pois, deixar de nos confrontar com esta questão. $O$ debate que problematiza a comunidade humana, ou seja, que interroga a relação entre espaço público e opinião pública e o modo de organizarmos a vida em comunidade, tem levado muitos investigadores a falar de "democracia possível", "revitalização política do espaço público", "requalificação democrática do espaço público", insistindo na intervenção do público na política e assinalando as formas de resistência e de reinvenção da política ${ }^{14}$. Por sua vez, é em termos semelhantes a estes que prossegue o debate, tanto no campo científico de educação para os média ou de literacia mediática, como no campo da economia política. ${ }^{15}$

No tempo tecnológico, a questão do espaço público, da opinião pública e da organização da vida em comunidade, pode ser problematizada pelo menos a partir de três

\footnotetext{
13 Esta expressão retoma o título do Prefácio que escrevi (Martins, 2006) para o livro de Teresa Ruão, Marcas e identidades.

14 Veja-se, por todos, João Pissarra Esteves em O Espaço público e os média (2005, pp. 25, 35, 39, 94, 100). Convocando uma primeira página do New York Times, Pissarra Esteves chama a atenção para "a emergência de uma segunda grande super-potência mundial - precisamente, a Opinião Pública" (Ibidem 25).

${ }^{15}$ Advogam Sara Pereira et al. (2014): "A Educação para os Media é um processo pedagógico que procura capacitar os cidadãos para viverem de forma crítica e interventiva a 'ecologia comunicacional' dos nossos dias". E escreve Estrela Serrano, no prefácio a uma obra de Manuel Pinto et. al. (2011): "A literacia para os média, entendida como o conjunto de competências e conhecimentos que permitem aos cidadãos uma utilização consciente e informada dos meios de comunicação social, representa uma componente essencial do processo Comunicativo". E conclui: "A importância da literacia para os média é hoje reconhecida como uma componente inalienável da cidadania, tendo sido objecto da Directiva 2007/65/CE do Parlamento Europeu e do Conselho, de 11 de Dezembro de 2007, nela se defendendo que "[a]s pessoas educadas para os media são capazes de fazer escolhas informadas, compreender a natureza dos conteúdos e serviços e tirar partido de toda a gama de oportunidades oferecidas pelas novas tecnologias das comunicações, [estando] mais aptas a protegerem-se e a protegerem as suas famílias contra material nocivo ou atentatório".

No que concerne à economia política, veja-se The Handbook of Political Economy of Communications, editado por Janet Wasco, Graham Murdock e Helena Sousa (2011). E atente-se, sobretudo, no estudo de Helena Sousa e Joaquim Fidalgo (pp. 283-303). Analisando a "regulação do jornalismo", em Portugal, interrogam estes autores o sentido dos códigos, da ética e dos conselhos jornalísticos, tanto profissionais como estatais, que visam "promover a qualidade dos discursos mediáticos e, em consequência, a qualidade das instituições democráticas, em geral” (Sousa e Fidalgo, 2011, p. 284).
} 
eixos de significação: um eixo que combina a técnica e a ética; um outro que articula a estética e a ética; e um terceiro eixo, que faz funcionar no mesmo plano a técnica e a estética.

O eixo que combina a técnica e a ética inscreve-se no quadro epistemológico da modernidade. Figura a emancipação histórica por injeção e mobilização tecnológicas. Por sua vez, a técnica é entendida como os modernos dispositivos tecnológicos, que incluem os média e que asseguram a mediação simbólica da nossa experiência atual. Neste entendimento, é tarefa da ética equacionar as normas universais que enquadrem a atividade tecnológica, designadamente a atividade mediática ${ }^{16}$.

O eixo que articula estética e ética remete para um quadro de pensamento pós-moderno. A pragmática hedonista e estetizante de Maffesoli (1979; 2000) constituiria uma ilustração desta atitude teórica, a qual, no entender de len Ang (1998, p. 78), é uma atitude conservadora. O otimismo social e cultural que a caracteriza permitir-lhe-ia adotar uma atitude conciliadora com a sociedade de consumo, interpretando-a, por um lado, como uma resposta positiva aos desejos do consumidor, e por outro lado, como uma resposta que promove mudanças sociais, na moda, nos estilos de vida e nos produtos. É uma resposta que "sucumbe a uma atitude de 'vale tudo'", conclui len Ang (Ibidem). Sendo autopoiética, advoga, com efeito, uma "ética da estética" (Maffesoli, 1990) e remete para um relativismo diletante e descomprometido, que se consome, com manifesto deleite, num pluralismo de jogos e simulacros. A questão do espaço público e da cidadania, ou seja, a questão da comunidade democrática não se inscreve neste regime de pensamento. $O$ tribalismo pós-moderno opera a "transfiguração da política" (Maffesoli, 1992): o sentido de comunidade esgota-se naquele que me é próximo, naquele com quem partilho uma emoção. No quadro do pensamento ético-estético, a técnica tem um caráter meramente lúdico e mágico, exercendo uma função de remitificação e reencantamento do mundo. ${ }^{17}$

O eixo que faz funcionar no mesmo plano a técnica e a estética é também, a meu ver, moderno. Caracteriza-o, todavia, um pessimismo histórico. Sendo, entretanto, "motivado por uma compreensão profunda dos limites e falhanços daquilo a que Habermas chamou 'o projeto inacabado da modernidade'" (len Ang, 1998), esta atitude epistemológica abre a alguns dos debates essenciais da contemporaneidade. Dado que não remete para normas universais que meçam todos os enunciados, este eixo de sentido faz declinações decetivas do público: e é "público fantasmagórico", para Lippmann (1925); "público simulacral", para Baudrillard (1981, p. 42); "sobrevivência simulacral" e espectral, no caso de Bragança de Miranda (1995).

Dos três eixos de sentido assinalados, é meu entendimento que apenas o eixo que combina a técnica com a estética interroga a natureza atual da técnica. O eixo técnico-ético moraliza a técnica: por um lado, procura controlá-la através de normas universais;

\footnotetext{
${ }^{16}$ Há quem considere o eixo de sentido técnico-ético como "pós-metafísico" (Esteves, 2005, pp. 39, 92). A meu ver, todavia, não creio que seja adequado fazê-lo, dado que este eixo de sentido assenta numa racionalidade forte, com o recurso ao critério de juízo último, com normas universais que medem os enunciados e com enunciados que têm um conteúdo exclusivamente cognitivo.

${ }^{17}$ Para Maffesoli, a tecnologia é do domínio do festivo, da intensidade e da jubilação: "O imaginário, a fantasia, o desejo de comunhão, as formas de solidariedade, as diversas entreajudas caritativas [afinal de contas, os valores proxémicos, domésticos, banais, da vida quotidiana] encontram na Internet e no 'ciberespaço' em geral vetores particularmente performantes" (Maffesoli, 2000, p. 14).
} 
por outro, promove o seu bom uso. Por sua vez, o eixo ético-estético celebra a técnica como uma remitificação da existência, jungindo arcaísmo e tecnologia'18. Em contrapartida, o eixo técnico-estético problematiza a natureza da técnica, vendo nela a realização da razão como controlo (a 'controllvernunft' de que fala Odo Marquard) e, simultaneamente, a modelação da nossa sensibilidade e emotividade, de modo a produzir o efeito cada vez mais alargado de estetização do mundo.

Entre outros debates essenciais da contemporaneidade a que este eixo procura dar resposta, assinalo as seguintes: a natureza da técnica na era do computador e uma nova teoria da imagem; o "bloco alucinatório" constituído pela ligação da técnica com a estética (com referências precisas a Benjamin, McLuhan, Debord e Deleuze, por exemplo); uma revisão da teoria da violência, da dominação e do controlo; uma problematização da experiência humana e do seu progressivo empobrecimento, com a reanimação de uns tantos conceitos e o depuramento de outros: alienação, anestesiamento, narcose, simulacro, congelamento dissimulado do mundo - um percurso por onde passam, entre outros, Benjamin, Musil, Debord, Klossowski, Deleuze, Baudrillard, Perniola e Agamben.

Não creio, com efeito, que a ideia de crise da modernidade, como "manipulação" e como "fechamento democrático", para que concorrem os média em boa medida, possa ser resolvida a golpes de fé no futuro, de auto-reflexividade e de ética, como acontece no caso dos debates desenvolvidos em torno do eixo técnico-ético ${ }^{19}$. A meu ver, a opção epistemológica que se centra no eixo de sentido técnico-estético tem manifestos efeitos emancipadores, embora com a vantagem de não apresentar a estrutura dramática de uma redenção final, dado exprimir a modernidade trágica, própria da era mediática, uma modernidade que diz a crise desta época, o seu mal-estar, a sua melancolia (Martins, 2003; 2002a; 2002d). No entanto, precipitada na imanência e jogando tudo no presente (Maffesoli, 1979), esta modernidade não pode deixar de figurar o horizonte de uma comunidade partilhada, sonhando com a redenção do humano. E também a move o apego à liberdade e a anima a erótica gozosa de um corpo que há que dar à comunidade. No modo como vejo as coisas, a era mediática, privada que está de normas universais que a destinem, é posta à prova no combate por uma "democracia a vir" (Martins, 2003).

Como assinalei, o atual funcionamento dos média anda associado à ideia de crise da modernidade. O tema já não é novo: por meados do século XIX, Alexis de Tocqueville via como irreversível o divórcio entre crítica e opinião. ${ }^{20} \mathrm{E}$ na Viena do princípio do século XX, à frente do Fackel, Karl Kraus garantia que o jornalismo comia o pensamento (Bouveresse, 2001).

\footnotetext{
${ }^{18}$ Como assinala Michel Maffesoli (2011, p. 17), "a tecnologia pós-moderna participa do reencantamento do mundo".

${ }^{19}$ Este entendimento tem, todavia, enérgicos defensores. Um deles é João Pissarra Esteves. Veja-se, por exemplo, o que escreve em $O$ Espaço Público e os Media. Depois de assinalar que a atual crise do espaço público se deve à "quebra dos princípios universais constitutivos da própria ideia de Espaço Público (liberdade e igualdade)", conclui: a resistência do espaço público à sua própria crise (todos os sinais e esforços de revitalização) "deixa transparecer a motivação primordial de uma experiência mais rica de cidadania, que inspira e actualiza os princípios universais atrás referidos: uma sociedade civil (identidades, associações e movimentos sociais) mobilizada em torno de um sistema mais amplo de liberdades e da criação de condições de uma maior igualdade a nível das relações sociais" (Esteves, 2005, pp. 100-101).

${ }^{20}$ Para Alexis de Tocqueville (1981, pp. 17-18), a crítica dobrou perante a opinião, cuja força "já não persuade com as convicções, apenas as impõe e as faz penetrar nos espíritos através de uma espécie de imensa pressão exercida sobre a inteligência de cada um".
} 
Bem sei que a nossa modernidade tem um grande potencial de auto-reflexividade. Por exemplo, naquilo que apresenta como uma "reescrita da modernidade", Jean-François Lyotard (1988, p. 202), denuncia como um mito "o projecto de emancipar a humanidade pela ciência e pela técnica" e assinala mesmo que a crítica deste simulacro "há muito que está a ser conduzida pela própria modernidade" ${ }^{21}$. Não estou, todavia, convencido de que a ideia de modernidade como projeto inacabado, ou então inacabável, possa fundar-se numa conceção universalista de liberdade. A ideia universalista de liberdade entrou em crise exatamente pelo seu caráter universalista, que a tornou apta para uma mobilização emancipatória global, também ela em crise. A meu ver, toda a ideia de projeto global é problemática, em termos sociológicos. No modo como entendo as coisas, para um sociólogo, mais importante do que as condições de possibilidade de uma comunidade, são as condições de existência concreta dessa comunidade, que configuram sempre um campo de forças sociais imanentes a esse campo específico. É neste sentido, aliás, que entendo a obra e o legado de Michel Foucault (1976), primeiro, e de Pierre Bourdieu (1989), depois.

Não quer isto dizer que seja possível considerar a emancipação histórica ao nível dos interesses, isolando-a, entretanto, de considerações epistémicas. Explicitando um ponto de vista de Michel Foucault, Paul Rabinow (1985: 93-94) invoca, neste sentido, Max Weber e sublinha: o Capitalista "não era só o homo economicus que negociava e fabricava navios, mas era também um indivíduo que via os quadros de Rembrandt, desenhava os mapas do mundo e não deixava de se inquietar com o seu destino". Estas atividades, continua Rabinow (Ibidem), "pesavam maciçamente sobre a realidade do Capitalista e inflectiam os seus comportamentos".

É exatamente pelo facto de fundarem o sentimento de identidade pessoal, e também o sentimento da realidade do mundo, que as práticas epistémicas fundam um regime de interação, ou seja, produzem um sentido. Deste modo, a indagação do objeto de estudo das ciências sociais, ou seja, a questão da ação social, obriga a considerar o regime do olhar em que assenta a peculiar forma de vida de uma sociedade: modos de dizer (as retóricas) e modos de ver (as hermenêuticas). Interrogar os interesses que regem a forma de vida de uma sociedade, é, pois, também fazer considerações de tipo epistémico.

Nestes exatos termos, parece-me perfeitamente ajustada a uma reescrita da modernidade a ideia de Bragança de Miranda (1995, pp. 129-148), que considera a atual utopia tecnológica de um agora virtual como a forma final da sobrevivência simulacral do espaço público. Na utopia tecnológica joga-se, com efeito, o velho esquema mítico que do Jardim do Éden à Torre de Babel e à sua atual translação na ideologia da cibercultura, fantasia uma sociedade de conhecimento total e de comunicação universal (Martins, 1998).

Quando nos anos setenta do século passado Pierre Bourdieu (1973) escreveu "L'opinion publique n'existe pas", o que aí se jogava, a meu ver, era já a denúncia de uma ficção idealista e universalista de espaço público, uma ficção, verificada nas sondagens e de que se alimentam em permanência os média, eles que, aliás, a criaram. Na mesma

${ }^{21}$ Sobre este assunto, ver "Comunicação e Cidadania" (Martins, 2008, pp. 20-21). http://repositorium.sdum.uminho.pt/ handle/1822/25364 
ordem de ideias, Daniel Bougnoux (2002, p. 277) já falava, há mais de uma dúzia de anos, da conivência fatal entre média, empresas de sondagens e políticos.

Indubitavelmente, os média não contribuem apenas para um fechamento da democracia. Nos média também residem possibilidades, mesmo que o seu papel seja, nos nossos dias, de uma grande equivocidade. Transferindo-se de armas e bagagens para a órbita do poder, os média encenam, hoje, o país real e os seus problemas concretos, sem qualquer correspondência com a realidade. $E$, além disso, blindam o espaço público à voz dos cidadãos. Entretanto, os reguladores dos média, habitualmente assinalados, por um lado o dinheiro (ou seja, o Mercado), por outro lado a política (isto é, o Estado), não estão à altura de explicar a estetização da política e do espaço público: o eixo de sentido que conjuga a técnica com a ética permite que se formule a questão estética, mas não permite resolvê-la. A meu ver, a dissolução da ideologia estética, de que falaram Paul de Man (1998) e Terry Eagleton (1993), obriga a que num primeiro momento seja considerado o bloco que na atualidade a técnica compõe com a estética.

\section{TÉCNICA E ESTÉTICA — RELENDO BENJAMIN}

A crítica de Habermas (1962) à conceção burguesa de espaço público recaiu no facto de esse espaço constituir uma falsa universalização e de impor a necessidade de o realizar verdadeiramente. Se bem observarmos, esta tese glosa e revê a ideia de Marx sobre o fim do capitalismo: o seu advento precipita o fim da divisão entre Estado e Sociedade Civil e faz desaparecer o próprio Estado.

De um ponto de vista comunicacional, este entendimento é todavia redutor, por não atender às razões técnicas e estéticas. Porém, a consideração destas razões encontrámo-la já em Marshall McLuhan (1962; 1964). Em The Gutenberg Galaxy, não apenas a modernidade é indissociável da mecanização da escrita, ou seja, da imprensa de Gutenberg, como também essa forma de expressão se adequa bastante bem ao espaço público clássico, onde a imprensa desempenha um papel essencial. É verdade que esse espaço não se esgota numa explicação técnica, mas parece-me incontestável que é inseparável dela. E é de esperar que sofra novas transformações, à medida que vão surgindo outras tecnologias mediáticas. Por outro lado, em Understanding Media, é já patente a fusão de techné e de aesthesis, com os média a serem figurados como extensões da sensibilidade humana.

A associação de técnica e estética é, todavia, realçada por Walter Benjamin, já nos anos 30, quando analisa o surgimento da fotografia, do cinema e da rádio, novos média para a época - o preciso momento em que os fascismos europeus se implantavam. Benjamin mostra-nos que o tipo de sujeito pressuposto na época literária, um sujeito racional e auto-controlado, representa bem mais a vontade coletiva do que os indivíduos empíricos. Quando considerados em conjunto, os indivíduos logo desaparecem, sublimados pela figura de uma "discussão" no espaço público. Entretanto, com a fotografia, o cinema e a rádio, que produzem e administram emoções, os indivíduos não são mobilizados em conjunto, mas individualmente. Como bem o assinala Siegfried Kracauer (1963), os indivíduos ainda podem ser vistos como "ornamento" nos filmes de Leni Riffensthal, mas 
a lógica deste processo vai no sentido de a mobilização recair sobre cada um dos indivíduos, agora envolvidos, um a um, afecionalmente. Ou seja, na época clássica, os sujeitos são tendencialmente racionais, tornando-se todavia totalmente racionais enquanto sujeito coletivo. Mas na nova situação tecnológica, deixamos de poder reunir politicamente os indivíduos. O mais que podemos fazer é agrupá-los, económica e estatisticamente. Em suma, a visão clássica de espaço público é ilusória, embora o não seja menos a conceção que insiste num espaço público, nas novas condições tecnológicas e económicas.

Por outro lado, a convocação da estética no contexto tecnológico não se cinge, de modo nenhum, ao recorte epistemológico desta disciplina. Falo de estética por relação à sensibilidade, à emoção, aos sentidos, enfim, à afeção. E é essa a razão pela qual se diz que a nova sensibilidade é híbrida - são as máquinas produzidas pela ciência que mobilizam as afeções e as monetarizam.

Este ponto de vista já está presente em Walter Benjamin (1936), quando critica a maneira como as categorias estéticas são usadas politicamente. $\mathrm{Na}$ sua perspetiva, os novos meios técnicos, que precipitam o desencantamento do mundo, ao anularem as categorias "metafísicas" da "criatividade, genialidade, valor eterno e secreto" (Benjamin, 1992, pp. 73-74), enfim as categorias daquilo a que chama "aura", são usados em certas circunstâncias para criar um fascínio de massas. Ao montarem um espetáculo, em que ilusoriamente as massas acreditam participar, os novos meios técnicos remagificam o mundo em permanência, operando o retorno do arcaico no atual. Mas desta análise de Benjamin não se segue que o advento dos novos meios técnicos tenha como único efeito a "desarticulação das massas". Pelo contrário, as novas técnicas também apoiam a entrada das massas na história, reforçando o direito de elas poderem afirmar-se enquanto sujeito. Esta circunstância faz eclodir a crise das relações de propriedade sobre que assentavam os valores de "criatividade, genialidade, valor eterno e secreto".

Benjamin privilegia esta tensão, que é interna à fotografia, ao cinema e à rádio (e, nos dias de hoje, a outros novos média), e ataca a política de fascinação das massas, que resulta do uso que os poderes dominantes fazem das novas técnicas. É verdade que Benjamin reconhece às vanguardas um efeito de choque no combate à reaurização (remagificação) do mundo. Mas as novas técnicas, como é o caso do cinema, provocam por si mesmas esse choque, levando-nos ao "inconsciente óptico" (Ibidem, p. 105), à realidade oculta da fantasmagoria, que tudo envolve.

$\mathrm{Na}$ análise de Benjamin existe, pois, esta dupla dimensão: o reconhecimento do fascínio das massas, produzido pelos média, e também as potencialidades "revolucionárias", que Benjamin atribui às novas técnicas. Segundo as palavras deste autor alemão, o cinema pode promover, em certos casos, "uma crítica revolucionária das relações sociais, ou mesmo das de propriedade" (Ibidem, p. 96). Se atendermos ao contexto em que é utilizada, esta passagem de Benjamin parece um tanto tímida e dubitativa. Mas tem uma importância decisiva, uma vez que coloca de frente a questão que nos importa, a de as novas técnicas terem potencialidades de crítica e de rutura, enfim de produção do humano.

O texto em questão analisa fundamentalmente o cinema, com Benjamin a procurar determinar-Ihe as "funções revolucionárias" (Ibidem, p.103). E não me parece adequado 
concluir que em Benjamin prevalecem as críticas à nova dominação emocional. Em meu entender, este ponto de vista falha o essencial, uma vez que Benjamin atribui às técnicas a capacidade de alterar mesmo a nossa relação ao real: "o cinema, através de grandes planos, do realce de pormenores escondidos em aspectos que nos são familiares, da exploração de ambientes banais com uma direcção genial da objectiva, aumenta a compreensão das imposições que regem a nossa experiência e consegue assegurar-nos um campo de acção imenso e insuspeitado. As nossas tabernas, as ruas das grandes cidades, os nossos escritórios e quartos mobilados, as nossas estações ferroviárias e as fábricas, pareciam aprisionar-nos irremediavelmente. Chegou o cinema e fez explodir este mundo de prisões com a dinamite do décimo de segundo, de forma tal que agora viajamos calma e aventurosamente por entre os seus destroços espalhados" (Ibidem, pp. 103-104). E a análise de Benjamin prossegue com o tratamento das questões conexas do "teste", do "exame", da "distracção", tópicos que decorrem da determinação deste "inconsciente óptico" do real (Ibidem, p. 105) revelado pelo cinema. É o inconsciente ótico que nos abre ao "inconsciente pulsional", conceito que Benjamin retoma de Freud e sobre o qual se eleva a montagem do espetáculo.

\section{Os Estudos Culturais como Novas Humanidades}

Tanto o meu ponto de partida como a minha linha de argumentação foram no sentido de considerar os Cultural Studies como as novas humanidades. Não creio, no entanto, que o meu ponto de vista tenha aberto um caminho inteiramente novo. Porque outros investigadores, antes de mim, procuraram romper neste sentido. Convoco dois exemplos, o de António Fidalgo, num estudo de 2008, e o de Sofia Sampaio, num estudo mais recente, de 2013. Ambos parecem aproximar-se do ponto de vista que aqui proponho. É verdade que a proposta de Sofia Sampaio é mais mitigada que a de António Fidalgo. No estudo que publicou, em 2013, na revista Culture Unbound, com o título "Portuguese Cultural Studies/Cultural Studies in Portugal" (Sampaio, 2013), Sofia Sampaio parece insistir mais na relação dos Cultural Studies com a "nova economia": os Estudos Culturais ocupar-se-iam das indústrias culturais e estas fariam parte da "nova economia", enquanto "indústrias criativas" (Sampaio, 2013, p. 83). Esse seria "um modelo desenvolvido pelo New Labor de Tony Blair na segunda metade dos anos noventa, que chegou oficialmente a Portugal entre 2005/2011, através do governo socialista de José Sócrates" (Ibidem, p. 79) 22. Convocando Miller \& Yúdice (2002), Garnham (2005) e Ross (2009), Sofia Sampaio (Ibidem, p. 79) adverte-nos que a "nova economia" está largamente dependente "da expansão das novas tecnologias da informação (sobretudo software, jogos de computador e publicação electrónica), além da extração de valor dos direitos de propriedade intelectual". Por outro lado, assinala que foi a elevação da

\footnotetext{
${ }^{22}$ Embora, para Sofia Sampaio, "a adoção do modelo político das indústrias criativas tenha sido responsável pelo súbito interesse institucional nos estudos culturais" (Sampaio, 2013, p. 79), esta investigadora do Centro em Rede de Investigação em Antropologia (CRIA) entende que os Acordos de Bolonha, assinados em 1999, sobre a construção de uma área comum europeia para a Educação Superior, desempenharam, de igual modo, um papel relevante nesta viragem das humanidades, sobretudo ao encorajar a interdisciplinaridade e a flexibilização do currículo (Ibidem).
} 
cultura a "chave da atividade económica", que modelou em Portugal a agenda dos estudos culturais (Ibidem, p. 83).

No entanto, tendo em conta a linha argumentativa desta investigadora do Centro em Rede de Investigação em Antropologia (CRIA), eu diria que é plausível tirar a conclusão de que os Estudos Culturais são as novas humanidades, pela simples razão de que, em termos gerais, estamos perante um movimento que as aproxima dos quatro pilares propostos por Johan Fornäs (1999, p. 132) para os identificar: "cultura, comunicação, contextualização e crítica". ${ }^{23}$ Este movimento, no sentido da 'complexidade' (Grossberg, 2010, pp. 16-17, 30,40), e também os efeitos na academia da viragem para o mercado, teriam a virtualidade de salvar as humanidades do "declínio do paradigma dos estudos literários" (Sampaio, 2013, p. 80) e dos laivos de ressentimento que o tem atormentado (Ibidem, p. 83).

De igual modo António Fidalgo, num texto que escreveu em 2008, a que deu o título "As novas humanidades", se aproximou do ponto de vista de que os Cultural Studies podem ser encarados como as novas humanidades. Radicalizou, todavia, este argumento, ao tomar as Ciências da Comunicação, tout court, como as "Novas Humanidades" (Fidalgo, 2007).

Eu próprio segui esta linha de raciocínio, de que os Estudos Culturais concretizam uma deslocação, que ocorreu nas humanidades e as infletiu no sentido das Ciências Sociais, e especificamente no sentido das Ciências da Comunicação. Fi-lo em dois estudos que realizei, em 2010 e 2011 , o primeiro aquando da criação do doutoramento em Estudos Culturais UM/UA (Martins, 2010a), o segundo içando-a a principal argumento do livro que então escrevi (Martins, 2011a). ${ }^{24}$

De acordo com a tradição dos Cultural Studies, o vínculo que importa esclarecer nas abordagens sobre a cultura é sempre o da sua relação com o poder, o que quer dizer, que a atenção deve recair, sempre, sobre as apropriações da cultura no quotidiano, pelos mais diversos atores e agentes sociais, sejam eles grupos ou movimentos (Martins, 2010a; 2011a).

\footnotetext{
${ }^{23}$ Sofia Sampaio $(2013$, p. 76$)$ chama, todavia, a atenção para o facto de a agenda crítica e contextualizadora dos Estudos Culturais se encontrar sobretudo associada aos centros de investigação de Ciências Sociais. E dá como exemplos: o Centro de Estudos de Comunicação e Sociedade (CECS), da Universidade do Minho, o Centro de Estudos Sociais (CES), da Universidade de Coimbra, e o Centro em Rede de Investigação em Antropologia (CRIA). Na realidade, até é frequente nas Faculdades de Letras, sobretudo nos meios dos estudos literários e dos "estudos ingleses e americanos" (Ibidem, p. 74), os Estudos Culturais serem olhados com alguma suspeição. Nesse sentido, referindo-se, especificamente, ao programa doutoral UM/UA, criado em 2010 e na dependência direta do Centro de Estudos de Comunicação e Sociedade (CECS), Sofia Sampaio assinala que é mais forte, em termos críticos e de contextualização, que o programa doutoral da Universidade Católica Portuguesa, do pólo de Lisboa, criado no mesmo ano, mas na dependência de um centro de estudos literários, o Centro de Estudos de Comunicação e Cultura (CECC). A linha teórica deste último, considera Sofia Sampaio, inspirada na tradição alemã da Kulturkritik, é "bastante ambígua", na sua relação com os Estudos Culturais; e o programa "é mais fraco, tanto na contextualização como na crítica", incidindo todavia, com mais clareza, "numa agenda orientada para o empreendedorismo", dado que tem como principal objetivo “a 'integração profissional dos estudantes'” (Ibidem).

${ }^{24}$ O livro Crise no castelo da cltura - Das estrelas para os ecrãs (Martins, 2011a) estabelece, na primeira parte, a relação entre "Os Estudos Culturais e as Ciências da Comunicação", a qual, por sua vez, está organizada em cinco capítulos: (1) "Os Estudos Culturais"; (2) "Os estudos da Comunicação e o contemporâneo"; (3) "As Ciências da Comunicação - um projecto da modernidade"; (4) "O visível e o invisível das práticas sociais"; (5) "Para um 'politeísmo' metodológico nos Estudos Culturais".
} 
Persistem, todavia, indefinições sobre o desenvolvimento dos Estudos Culturais em Portugal, e de igual modo, ambiguidades sobre o próprio conceito. ${ }^{25}$ Por essa razão, refere ainda Sofia Sampaio, alguns projetos de investigação em Portugal (particularmente projetos de ensino) tomam os Estudos Culturais como equivalentes a meros estudos sobre a cultura (Sampaio, 2013, p. 76). Penso que este é, todavia, um equívoco que a minha proposta procurou esclarecer: os Estudos Culturais declinam as atuais vertigens do humano, razão pela qual podem ser encarados como as novas humanidades.

\section{REFERÊNCIAS}

Agamben, G. (1995). Moyens sans fin. Notes sur la politique. Paris: Payot \& Rivages.

Aguiar e Silva, V. (2008). Genealogias, lógicas e horizontes dos estudos culturais. In R. Goulart, M. Fraga, \& P. Meneses, O Trabalho da Teoria - Colóquio em Homenagem. Ponta Delgada: Universidade dos Açores.

Ang, I. (1998). The performance of the sponge: mass communication theory enters the postmodern world. In K. Brants, J. Hermes e L. van Zoonen (Eds.), The Media in Question (pp. 77-88). Londres: Sage.

Baptista, M. M. (2009). Estudos culturais: o quê e o como da investigação. Revue Életronique d'Études Françaises, automne/hiver, 451-461. http://revistas.ua.pt/index.php/Carnets/article/view/466/422

Barthes, R. (1964). Rhétorique de l'image. Communications, 4, 40-51.

Baudrillard, J. (1981). Simulacres et simulation. Paris: Galilée.

Benjamin, W. (1992) [1936]. A obra de arte na era da sua reprodutibilidade técnica. In Walter B., Sobre Arte, Técnica, Linguagem e Política (pp. 71-110). Lisboa: Relógio D’Água.

Soares, B. (1998). Livro do desassossego. Lisboa: Assírio \& Alvim.

Bougnoux, D. (2002). Comunicação e informação na modernidade. Comunicação e Sociedade, 4, $275-284$. http://revistacomsoc.pt/index.php/comsoc/article/view/1290/1231

Bourdieu, P. (1989). O poder simbólico. Lisboa: Difel.

Bourdieu, P. (1980) [1973]. L'opinion publique n'existe pas. In P. Bourdieu, Questions de Sociologie (pp. 222235). Paris: Minuit.

Bouveresse, J. (2001). Schmock ou le triomphe du journalisme - La grande bataille de Karl Kraus. Paris: Seuil.

De Man, P. (1998) [1996]. La Ideología estética. Madrid: Ediciones Cátedra.

Derrida, J. (1967). L'écriture de la Différence. Paris: Seuil.

Durand, G. (1969). Les structures anthropologiques de l'imaginaire. Paris: Bordas.

Eagleton, T. (1993) [1990]. A ideologia da estética. Rio de Janeiro: Zahar Editora.

\footnotetext{
${ }_{25}^{25}$ Maria Manuel Baptista (2009) assinala, logo na abertura de um estudo que realizou em 2009: "A área de Estudos Culturais é intrinsecamente paradoxal, objecto de discussão e incerteza, caracterizando-se por uma forte presença académica nos discursos intelectuais, revela discórdias internas profundas em relação a praticamente tudo: sobre para que serve, a quem servem os seus resultados, que teorias produz e utiliza, que métodos e objectos de estudo lhe são adequados, quais os seus limites, etc.".
} 
Esteves, J. P. (2005). O espaço público e os media. Lisboa: Colibri.

Fidalgo, A, (2008). As novas humanidades. Covilhã: UBI, Col. Lusosofia, pp. 3-14 www.lusosofia.net

Fornäs, J. (Ed.) (1999). Advancing cultural studies: report from an international workshop at Södergarn, February, pp. 113-158. http://www.isak.liu.se/acsis/publikasjoner/1.91935/acsreport1999.pdf

Foucault, M. (1976). Histoire de la Sexualité, I. La Volonté de Savoir. Paris: Gallimard.

Gadamer, H.-G. (1976). Vérité et méthode. Paris: Seuil.

Garnham, N. (2005). From cultural to creative industries: An analysis of the implications of the 'creative industries. Approach to arts and media policy making in the United Kingdom. International Journal of Cultural Policy, 11, (1), 15-29.

Grossberg, L.(2010). Cultural studies in the future tense. Durham e Londres: Duke University Press.

Habermas, J. (1986) [1962]. L'espace publique. Paris: Payot.

Jünger, E. (1990) [1930]. La mobilisation totale, precedida por L 'État universel. Paris: Gallimard.

Klossowski, P. (1997) [1970]. La monnaie vivante. Paris: Ed. Payot \& Rivages.

Kracauer, S. (1963) [1995]. The mass ornament. Weimar Essays. Traduzido, editado, e com uma introdução de Thomas Y. Levin. Cambridge, Massachussetts, Londres: Harvard University Press.

Lippmann, W. (1925). The phantom public. Nova Yorque: Harcourt, Brace.

Lyotard, JF. (1993). Une fable postmoderne. In Jean- François, L., Moralités Postmodernes (pp. 79-94). Paris: Galilée.

Lyotard, JF. (1988). Réécrire la modernité. Les Cahiers de Philosophie, 5, pp. 193-203.

Macedo, M. L. (2013). Da diversidade do mundo ao mundo diverso da lusofonia: a reinvenção de uma comunidade geocultural na sociedade em rede. Tese de doutoramento em Ciências da Comunicação, na especialidade de Comunicação Intercultural, pela Universidade do Minho. http://repositorium.sdum. uminho.pt/handle/1822/28851

Maffesoli, M. (2011). L'initiation au présent. Cahiers Européens de l'Imaginaire, 3, 14-27.

Maffesoli, M. (2000). L'instant éternel. Le retour du tragique dans les sociétés postmodernes. Paris: Denoël.

Maffesoli, M. (1992). La transfiguration du politique. La tribalisation du monde. Paris: Grasset.

Maffesoli, M. (1990). Au creux des apparences. Pour une éthique de l'esthétique. Paris: La Table Ronde.

Maffesoli, M. (1979) [1998]. La conquête du présent. Pour une sociologie de la vie quotidienne. Paris: Desclée de Brower.

Martins, M. de L. (2013). The death body: mythes, rites and superstitions. Revista Lusófona de Estudos Culturais / Lusophone Journal of Cultural Studies, 1 (1), 135-160. http://estudosculturais.com/ revistalusofona/index.php/rlec/article/view/12/38

Martins, M. de L. (2011a). Crise no castelo da cultura. Das estrelas para os ecrãs. Coimbra: Grácio/CECS. http:// repositorium.sdum.uminho.pt/handle/1822/29167

Martins, M. de L. (2011b). Technologie et rêve d'humanité. Les Cahiers Européens de L'Imaginaire, 3, 56-61. http://repositorium.sdum.uminho.pt/handle/1822/24245 
Martins, M. de L. (2011c). Médias et mélancolie - Le tragique, le baroque et le grotesque. Sociétés, 111, 17-25. http://repositorium.sdum.uminho.pt/handle/1822/23866

Martins, M. de L. (2010a). Estudos culturais no Instituto de Ciências Sociais da Universidade do Minho". In M. L. Martins, Caminhos nas Ciências Sociais. Memória, Mudança Social e Razão. Coimbra: Grácio/CECS. http://repositorium.sdum.uminho.pt/handle/1822/29762

Martins, M. de L. (2010b). A mobilização infinita numa sociedade de meios sem fins. In: C. Álvares \& M. Damásio (Org.). Teorias e Práticas dos Media: Situando o Local no Global. Lisboa: Edições Lusófonas, pp. 267-275. http://repositorium.sdum.uminho.pt/handle/1822/24250

Martins, M. de L. (2010c). Linguagem, verdade e conhecimento. As Ciências da Comunicação e o contemporâneo. In A. S. Silva, Comunicação, Cognição e Media (pp. 77-86). Aletheia: Braga, Universidade Católica Portuguesa, http://repositorium.sdum.uminho.pt/handle/1822/24118

Martins, M. de L.s (2009). Ce que peuvent les images. Trajet de I'un au multiple. Les Cahiers Européens de I'Imaginaire, 1, 158-162. http://repositorium.sdum.uminho.pt/handle/1822/24132

Martins, M. de L. (2008). Comunicação e Cidadania. In M. L. Martins \& M. Pinto (Org.), Comunicação e Cidadania. Actas do $5^{\circ}$ Congresso da Sopcom (pp. 19-25). Braga: Centro de Estudos de Comunicação e Sociedade (CECS), http://repositorium.sdum.uminho.pt/handle/1822/25364

Martins, M. de L. (2007a). La nouvelle érotique interactive". Sociétés, 96, 21-27. http://repositorium.sdum. uminho.pt/handle/1822/23767

Martins, M. de L. (2007b). Nota introdutória. A época e as suas ideias. Comunicação e Sociedade, 12, 5-7. http://repositorium.sdum.uminho.pt/handle/1822/24115

Martins, M. de L. (2006). A memória sensorial, afectiva e corporal das marcas [Prefácio]. In T. Ruão, Marcas $e$ Identidades. Porto: Campo das Letras. http://repositorium.sdum.uminho.pt/handle/1822/30050

Martins, M. de L. (2003). Por uma democracia a vir. A Televisão de serviço público e a sociedade civil" [Prefácio]. In M. Pinto (Org.), Televisão e Cidadania (pp. 9-12). Braga: Núcleo de Estudos de Comunicação e Sociedade: Universidade do Minho.

Martins, M. de L. (2002a). "O trágico como imaginário da era mediática. Comunicação e Sociedade, 4, 73-79. http://repositorium.sdum.uminho.pt/handle/1822/24132

Martins, M. de L. (2002b). A linguagem, a verdade e o poder. Lisboa: Fundação Calouste Gulbenkian \& Fundação para a Ciência e a Tecnologia.

Martins, M. de L. (2002c). De animais da promessa a animais em sofrimento de finalidade. O Escritor, 18-20, 351-354. http://repositorium.sdum.uminho.pt/handle/1822/1676

Martins, M. de L. (2002d). Tragedy in modernity. Interact: Revista Online de Arte, Cultura e Tecnologia, 5, s/p. http://repositorium.sdum.uminho.pt/handle/1822/1788

Martins, M. de L. (1998). A biblioteca de Babel e a árvore do conhecimento. O Escritor (Lisboa), 11/12, 235240. http://repositorium.sdum.uminho.pt/handle/1822/30068

Martins, M. de L. (1994). A verdade e a função de verdade nas Ciências Sociais. Cadernos do Noroeste, 7, 5-18. http://repositorium.sdum.uminho.pt/handle/1822/25385

McLuhan, M. (1962). The Gutenberg galaxy. Toronto: Toronto University Press.

McLuhan, M. (1964). Understanding media. Londres: Routledge and Kegan Paul. 
Miller, T. \& Yúdice, G. (2002). Cultural Policy. Londres/Thousand Oaks: Sage.

Miranda, J. B. de (1995). Espaço público, política e mediação. Revista de Comunicação e Linguagens, 21-22,129-148.

Negroponte, N. (1995). Vida digital. Tradução de Sérgio Tellaroli. São Paulo: Companhia das Letras.

Nietzsche, F. (1988) [1887]. Genealogia da moral. São Paulo: Companhia das Letras.

Pereira, S. et al. (2014). Referencial de educação para os media para a educação pré-escolar, o ensino básico e o ensino secundário. Lisboa: Ministério da Educação e Ciência.

Perniola, M. (1993) [1991]. Do sentir. Lisboa: Presença.

Pinto, M. et al. (2011). Educação para os media em Portugal: experiências, actores e contextos. Lisboa: Entidade Reguladora para a Comunicação Social (ERC). http://www.erc.pt/pt/estudos-e-publicacoes/publicacoes

Rabinow, P (1985). Fantasia dans la Bibliothèque. Les représentations sociales sont des faits sociaux: modernité et post-modernité en anthropologie. Études Rurales, 97/98, 91-114.

Reis, C. (2005). A crise das humanidades. Público, 25/10/2005.

Rorty, R. (1994). Solidarité ou objectivité. In R. Rorty, Objectivisme, Relativisme et Vérité. Paris: PUF, pp. 35-55.

Ross, A. (2009). Nice work if you can get it: life and labor in precarious times. Nova Yorque e Londres: New York University Press.

Sampaio, S. (2013). Portuguese cultural studies / Cultural studies in Portugal: some thoughts on the making and remaking of a field. Culture Unbound. Journal of Current Cultural Research, 5, 73-88. http://www. cultureunbound.ep.liu.se/v5/ao7/cu13v5a07.pdf

Sloterdijk, P. (2000). La mobilisation infinie. Christian Bourgois Ed.

Sousa, H. \& Fidalgo, J. (2011). Journalism regulation. State power and professional autonomy. In J. Wasco, Graham, Murdock e H. Sousa (Org.) The Handbook of Political Economy of Communications (pp. 283303). Wiley-Blackwell Publishing / IAMCR.

Steiner, G. 1992 [1971]. No castelo do Barba Azul. Algumas notas para a redefinição da cultura. Lisboa: Relógio D’Água.

Tocqueville, A. de (1981) [1835/1840]. De la démocratie en Amérique, vol. 2. Paris: Garnier-Flammarion.

Wasco, J; Murdock, G; Sousa, H. (Org.) (2011). The handbook of political economy of communications. WileyBlackwell Publishing / IAMCR.

Virilio, P. (1995). La vitesse de libération. Paris: Galilée.

\section{ENDEREÇOS ELETRÓNICOS}

http://estudosculturais.com/portal/apresentacao/

http://estudosculturais.com/portal/redes/cultural-studies-network/ 
Moisés de Lemos Martins é professor de sociologia da cultura e da comunicação na Universidade do Minho (Braga, Portugal), sendo nesta universidade Diretor do Centro de Estudos de Comunicação e Sociedade (CECS), que fundou em 2001. É autor de vários livros, entre os quais: O Olho de Deus no discurso salazarista (1990) e Para uma inversa navegação - O discurso da identidade (1996), ambos nas Edições Afrontamento; A linguagem, a verdade e o poder - Ensaio de semiótica social (2002, Fundação Calouste Gulbenkian e Fundação para a Ciência e a Tecnologia); Crise no Castelo da Cultura - Das estrelas para os ecrãs (2011, Grácio Editor). Fundou, em 1999, a revista Comunicação $e$ Sociedade e, em 2013, Anuário Lusófono de Estudos Culturais. Preside, desde 2012, à Confederação Iberoamericana das Associações Científicas e Académicas de Comunicação, depois de ter presidido, de 2005 a 2015, à Associação Portuguesa de Ciências da Comunicação (Sopcom).

E-mail: moiseslmartins@gmail.com; moisesm@ics.uminho.pt

Centro de Estudos de Comunicação e Sociedade (CECS)- Universidade do Minho Instituto de Ciências Sociais, Campus de Gualtar 4710-057 Braga Portugal 